\title{
Exposure to print and word recognition processes
}

\author{
DAN CHATEAU and DEBRA JARED \\ University of Western Ontario, London, Ontario, Canada
}

\begin{abstract}
The effect of exposure to print on the efficiency of phonological and orthographic word recognition processes was examined by comparing two groups of university students having similar reading comprehension scores but different levels of exposure to print. Participants with a high level of exposure to print were faster and more accurate in naming pseudowords, in choosing the correct member of a homophone pair, and in making lexical decisions when nonwords were pseudohomophones. In the lexical decision task, low-print-exposure participants were more sensitive to the frequency of the orthographic patterns in the stimuli. The results of a form priming task demonstrated that high-print-exposure participants more quickly and strongly activated the orthographic representations of common words and subsequently more strongly activated the corresponding phonological representations. Even among successful students, differences in exposure to print produce large differences in the efficiency of both orthographic and phonological word recognition processes.
\end{abstract}

There is tremendous variation in the amount of time that people in our society choose to read. These differences in exposure to print may be an important source of individual differences in cognitive abilities. Stanovich (1993) pointed out that print contains declarative knowledge that is often not available in electronic media or oral sources. Print is also a richer source of vocabulary than speech or television (Hayes \& Ahrens, 1988). Stanovich and Cunningham (1992) provided evidence that people who have more exposure to these unique characteristics of print develop better vocabularies and more general knowledge than those who read much less, even when nonverbal intelligence and reading comprehension ability were statistically controlled.

Exposure to print may not only have an impact on the amount of declarative knowledge and vocabulary that an individual acquires but may also have a major impact on the act of reading itself. It is reasonable to expect that extensive practice in reading enhances the cognitive processes that are used to recognize words. This would be an important consequence of exposure to print, because greater automaticity in word recognition processes has been linked to higher levels of reading comprehension ability (e.g., Perfetti, 1985). In this study, we examined how exposure to print influences word recognition skills.

\footnotetext{
This research was supported by a Graduate Fellowship to the first author and Grant OGPO 153380 to the second author, both from the Natural Sciences and Engineering Research Council of Canada. This article was based on a master's thesis completed by D.C. under the supervision of D.J. A major portion of this paper was presented at the Seventh Meeting of the Canadian Society for Brain, Behavioural, and Cognitive Science, Winnipeg, Canada, June 1997. The authors thank Keith Stanovich for providing the Canadian version of the Author Recognition Test used in this research. Correspondence should be addressed to D. Jared, Department of Psychology, University of Western Ontario, London, ON, N6A 5C2 Canada (e-mail: djjared@julian. uwo.ca).
}

In particular, we attempted to determine whether greater exposure to print increases the ability to use knowledge of the relationships between orthography and meaning (orthographic processing efficiency), ${ }^{1}$ the ability to use knowledge of the relationships between orthography and phonology (phonological processing efficiency), or both. In this study, we also examined whether print exposure affects the relative speed with which orthographic and phonological representations are activated.

\section{Measures of Exposure to Print}

Three of the methods that have been used to assess an individual's level of exposure to print have serious shortcomings. Questionnaires and interviews (e.g., Guthrie, 1981; Walberg \& Tsai, 1984) require that respondents estimate the amount of time they read, which is very difficult to accomplish with an adequate degree of accuracy (Burt \& Kemp, 1991). Furthermore, both are susceptible to socially desirable responding (Paulhus, 1984). Another method, the daily activity diary, is much more accurate than questionnaires or interviews but is very time consuming and depends on the respondents' being faithful in filling out the diaries.

An alternative measure of exposure to print developed by Stanovich and West (1989) overcomes the limitations of the previous measures. The Author Recognition Test (ART) consists of 50 names of popular authors and 50 foil names listed in alphabetical order. Participants are asked to put a check beside the names of people whom they know to be authors and leave all other spaces blank. Because incorrect responses are subtracted from correct responses, scores are not inflated by guessing. It is important to note that the test does not reveal a person's absolute level of print exposure; it can only indicate how much a person reads, relative to the performance of other people on the same test. Stanovich and colleagues (Allen, Cipielewski, \& Stanovich, 1992; Cipielewski \& Stanovich, 
1992; Stanovich, 1993; West, Stanovich, \& Mitchell, 1993 ) demonstrated that the ART is a reliable and valid measure of people's relative exposure to print. McBrideChang, Manis, Seidenberg, Custodio, and Doi (1993) claimed that this recognition checklist is "among the purest and best measures of print exposure devised to date" (p. 237).

\section{Exposure to Print and Word Recognition Processes}

Stanovich and West (1989) used the ART to examine the effects of exposure to print on the processes involved in word recognition. Phonological processing efficiency was measured using a pseudoword naming task and a phonological choice task (Which pseudoword sounds like a real word? KAKE-DAKE). Performance on both tasks reflects phonological processing efficiency because the pronunciation of a pseudoword can be determined only through print-to-sound conversion and cannot be retrieved from memory. Orthographic processing efficiency was measured with an orthographic choice task (Which letter string is a real word? RUME-ROOM) and a homophone choice task (Which is a fruit? PAIR- PEAR). In both tasks, knowledge of the orthography of the correct target is necessary for one to make a decision, because the two alternatives always had the same pronunciation. If decisions are based on meanings activated by phonological representations, an incorrect response would be as likely as a correct response.

Stanovich and West (1989) found significant correlations between scores on the ART and performance on the phonological processing tasks and orthographic processing tasks, indicating that greater exposure to print was associated with improved phonological and orthographic processing capabilities. In a hierarchical regression analysis, the ART accounted for significant additional variance in performance on the orthographic processing tasks after the measures of phonological processing ability had been partialed out. Stanovich and West interpreted this pattern of results as indicating that print exposure contributes to the efficiency of orthographic processing and knowledge of English orthography independent of the contribution of phonological processing efficiency.

There was no indication in the correlational analyses that exposure to print had a differential impact on orthographic and phonological processes; the correlations between ART scores and orthographic processing scores (.32 for the orthographic choice task and .33 for the homophone choice task) were similar to the correlations between ART scores and phonological processing scores (.27 for the phonological choice task and .35 for the pseudoword naming task). In a further analysis, Stanovich and West (1989) compared the performance of participants having low reading comprehension scores and high ART scores with participants having high reading comprehension scores and low ART scores. They found that the high-print-exposure participants had significantly better performance on the phonological processing tasks than did the low-print-exposure participants. The high-print-exposure participants also had better performance on the orthographic processing tasks, but these differences were not significant. This suggests the possibility that print exposure may have a greater impact on phonological processing than on orthographic processing.

Lewellen, Goldinger, Pisoni, and Greene (1993) compared the performance of low- and high-ability readers on several word recognition tasks. Although the ART was not used to assign participants to groups, it was administered and found to correlate highly with the three selection tasks. Relative to the low-ability participants, the high-ability participants named words faster, made faster and more accurate lexical decisions when nonwords were legal letter strings, and rejected nonmembers in a semantic decision task more quickly and accurately. These results indicate that the high-ability participants had more efficient and more accurate word recognition processes than the low-ability participants.

Of greater interest is whether the differences between the groups are attributable to increases in orthographic processing efficiency, phonological processing efficiency, or both. Because the naming task used real words that can be named as a result of processing along the orthographic or phonological routes, it does not clearly tell us that any differences in performance are due to phonological processing, as would have been the case if pseudowords had been used. The lexical decision task used pseudowords that did not sound like real words when pronounced, and so performance on this task could also reflect phonological processing, orthographic processing, or both. However, the orthographic neighborhood size of the words in the lexical decision task was varied. The orthographic neighborhood size of a word was measured using Coltheart's $N$, which is the number of words that can be formed by changing a single letter of the word (Coltheart, Davelaar, Jonasson, \& Besner, 1977). Effects of number of orthographic neighbors have been taken to reflect orthographic processing (Andrews, 1992). Both groups of participants made faster decisions on words from dense neighborhoods than on words from sparse neighborhoods, but because there was no interaction between group and neighborhood density, we cannot conclude from this task that reading ability or print exposure has an impact on orthographic processing. There was some evidence from the semantic decision task, however, that orthographic processing is more efficient and accurate in the high-ability readers. The stimuli included homophone foils (e.g., animal: WAIL) and spelling controls (e.g., animal: WAVE) as in Van Orden's (1987) experiments. High-ability participants made fewer errors on homophone foils and had faster decision times on correctly rejected homophone foils than low-ability participants. Because homophone foils cannot be correctly rejected using phonological represen- 
tations, this result indicates that high-ability participants had more efficient and more accurate orthographic processes than low-ability participants.

There are several limitations to the two studies discussed above. Neither study provides firm evidence that exposure to print was responsible for observed differences in phonological and orthographic processes. The participants in Lewellen et al.'s (1993) study differed not only in score on the ART but also on Nelson-Denny vocabulary score and several other measures of verbal ability. Similarly, Stanovich and West (1989) did not partial out verbal ability before the ART variable was entered in the regression equation. It is possible that general verbal ability may be a stronger determiner of word recognition abilities than exposure to print. That is, people with greater verbal ability may be more likely to develop strong word recognition skills, which in turn may lead them to read more and score higher on the ART. The participants chosen for the present study differed in their ART scores but were matched for Nelson-Denny reading comprehension scores. This is a very conservative test of the effects of exposure to print on word recognition because, as mentioned earlier, an important determiner of reading comprehension ability is the efficiency of word recognition processes (e.g., Perfetti, 1985). When reading comprehension ability is equated, the variance in word recognition processes left to be accounted for by exposure to print is greatly reduced.

A second limitation of the Stanovich and West (1989) study is that the two tasks that were used as measures of orthographic processing (the orthographic choice task and the homophone choice task) and one of the tasks that was used as a measure of phonological processing (the phonological choice task) involved the processing of two discrete letter strings or words, rather than a single stimulus, in order to make a decision. As such, these tasks may involve decision processes not involved in normal word recognition. Also, the additional processes involved in the choice tasks cause decision latencies to be quite long, making it difficult to capture any subtle interactions between exposure to print and other variables.

In the present study, phonological processing ability was measured using a task in which one word was presented at a time; this was a pseudoword naming task similar to the one in Stanovich and West's (1989) study except that a different and larger set of pseudowords was used. In addition, two tasks were used to measure orthographic processing efficiency. One was a homophone choice task and was included to determine whether Stanovich and West's results replicate with a new and larger set of homophone pairs. In this new set, the frequency of the homophones was manipulated. The second orthographic task was a lexical decision task in which one stimulus was presented at a time. Word frequency and size of the orthographic neighborhood of the words were manipulated, as in Lewellen et al.'s (1993) study. However, in contrast to their study, the nonwords were all pseudohomophones, which sound like words when pronounced (e.g., BRANE).
Consequently, participants had to use orthographic processing to make their decisions. Furthermore, in the present study, half of the pseudohomophones were orthographically unusual and the other half of the pseudohomophones contained common orthographic patterns. If high-printexposure participants have better and more efficient orthographic processes than low-print-exposure participants, then they should perform both orthographic tasks more quickly and accurately than low-print-exposure participants. More specifically, the effects of word frequency are expected to be smaller for high-print-exposure participants than for low-print-exposure participants in both orthographic tasks because the benefits of exposure to a word likely decrease with increasing exposures (e.g., Van Orden, Pennington, \& Stone's, 1990, asymptotic learning hypothesis). High-print-exposure participants should also show a smaller effect of orthographic neighborhood size on their decision latencies for words. This prediction follows from the observation of smaller effects of neighborhood size for high-frequency words than for low-frequency words (Andrews, 1992). Stated another way, this finding suggests that the recognition of a word is less influenced by its orthographic neighbors the more often it is encountered. High-print-exposure participants have likely read each of the words in the study much more often than low-print-exposure participants and therefore should show a smaller effect of neighborhood size. In addition, high-print-exposure participants' decisions should be less affected by the typicality of the orthographic patterns in the pseudohomophones than should low-print-exposure participants' decisions. Taken together, if the orthographic processing ability of highprint-exposure participants is superior to that of lowprint-exposure participants, then high-print-exposure participants should be able to more quickly accept unwordlike words (low frequency, small neighborhood) and more quickly reject word-like pseudowords than lowprint-exposure participants.

The present study extended previous work in one additional way. A form priming lexical decision task (Forster, 1987; Forster \& Davis, 1991) was used to determine whether exposure to print affects the relative speed with which orthographic and phonological representations are activated. The critical primes and targets in the study were orthographically similar but phonologically dissimilar (e.g., touch-COUCH). Facilitation of the target relative to the unrelated prime condition (e.g., shall-COUCH) would indicate that a good-quality orthographic representation was developed from the brief presentation of a prime and that the phonological representation was either more weakly activated or not activated at all. Conversely, inhibition would indicate that the phonological representation was relatively more strongly activated than the orthographic representation. Half of the critical primes were high-frequency words, and the other half were lowfrequency words. It is possible that the orthographic representations of high-frequency words develop more quickly than the phonological representations, which 
would produce facilitation. In contrast, the quality of orthographic representations may be poorer for lowfrequency words, with the result that facilitation may be less likely. Two prime durations were used, 30 and $60 \mathrm{msec}$, because the relative strength of orthographic and phonological representations may vary during processing (Ferrand \& Grainger, 1992, 1993, 1994). Ferrand and Grainger (1993) found that facilitation due to orthographic overlap was greatest at $33 \mathrm{msec}$, whereas facilitation due to phonological overlap was greatest at $67 \mathrm{msec}$.

In summary, the present study replicated and extended Stanovich and West's (1989) and Lewellen et al.'s (1993) work on the effects of exposure to print on word recognition processes. Participants were matched on reading comprehension ability so that any effects of exposure to print could be more confidently attributed to that variable instead of general verbal ability. Two tasks (the homophone choice task and the lexical decision task) examined whether orthographic processing is enhanced by exposure to print, and one task (the pseudoword naming task) examined whether phonological processing is enhanced by exposure to print. A fourth task (form priming) attempted to determine whether exposure to print affects the relative speed with which orthographic and phonological representations are activated.

\section{METHOD}

\section{Participants}

Sixty-four undergraduate students at the University of Western Ontario participated in the study. The participants volunteered for the study as one method of earning credit in an introductory psychology class, or they were reimbursed for their time. All participants were native English speakers and had normal or corrected-to-normal vision. Half of the participants were in the high-print-exposure group, and the other half were in the low-print-exposure group.

The participants were selected from a larger group of students who participated in a prescreening session, during which the NelsonDenny Reading Comprehension Test (Form F; J. J. Brown, Bennett, \& Hanna, 1981) was administered using the 15-min time limit and a Canadian version of the ART (K. E. Stanovich, personal communication, August 15, 1995) was given. The participants who scored at least 18 on the ART were considered to be high in print exposure; those scoring 14 or less on the ART were considered to be low in print exposure. The participants were further selected so that the two groups were matched for performance on the Nelson-Denny comprehension test.

\section{Materials}

Homophone choice task. Eighty pairs of English homophones were used (see Appendix B in Jared, Levy, \& Rayner, 1999). One member of each pair was chosen to be the correct member. Half of the correct homophones were high-frequency words (mean frequency $=585.8),{ }^{2}$ and half were low-frequency words (mean frequency $=5.6$ ). Two lists were created such that each correct homophone was on the left in one list and the right on the second list, and an equal number of high- and low-frequency homophones appeared on each list. A synonym was selected for each correct homophone (e.g., recent: KNEW-NEW).

Lexical decision task. One hundred ninety-two monosyllabic stimuli were chosen. Half of these were words, and half were pseudohomophones. Half of each type of stimuli were four letters in
}

length, and half were five letters in length. Forty-eight of the words and 40 of the pseudohomophones in the study were experimental stimuli. The remaining stimuli were filler items.

The 48 experimental words were taken from Andrews (1992). Half had a frequency of at least 60 , and the other half had a frequency less than 10. Half of the words of each frequency had a large orthographic neighborhood (at least 9 neighbors) as measured by Coltheart's $N$; the other half had a small neighborhood (no more than 6 neighbors).

The 40 experimental pseudohomophones (see Appendix A) were developed for this study. Half had common orthographic patterns, and half had unusual orthographic patterns. The pseudohomophones with common orthographic patterns contained only highfrequency bigrams (e.g., REECH). The positional frequency of each bigram was greater than 100 per million; the overall frequency of each bigram, regardless of position, was greater than 2,500 per million (Solso \& Juel, 1980). The pseudohomophones with unusual orthographic patterns (e.g., CHUZE) contained at least one bigram with a very low frequency, both positional (less than 10) and overall (less than 600 ). The mean frequencies of the words from which the pseudohomophones were derived were 47.8 and 51.1 for the common and unusual orthography groups, respectively.

Pseudoword naming task. Eighty pronounceable pseudowords taken from P. Brown, Lupkcr, and Colombo (1994) were used. Half of the pseudowords were one syllable in length, and half were two syllables in length. Three of the stimuli were slightly altered from those used by P. Brown et al. The pseudoword SHUD was changed to SHUP, and PHAITLE was changed to PHAIBET. This was done because these stimuli could be pseudohomophones of the words SHOULD and FATAL. As well, the pseudoword SKORPARY was changed to SKORPAR. The original stimulus was intended to have two syllables but had three syllables.

Form priming task. The critical stimuli consisted of 48 monosyllabic prime/target word pairs (see Appendix B). All of the targets were low-frequency words (frequencies were less than 20). Half of the primes were low-frequency words, and half were high-frequency words (frequencies greater than 60). Each target was matched with an orthographically related prime that shared all but one letter with the target (e.g., touch-COUCH). Importantly, the word bodies of the primes were pronounced differently from the word bodies of their matched related targets. As a control condition, each target was also matched with an orthographically unrelated prime (e.g., shall$\mathrm{COUCH}$ ), in which there was no orthographic overlap. The unrelated prime-target pairs contained the same primes as in the related condition, but the items were switched so that the prime and target were not orthographically related. Two lists were developed, with half of the prime -target pairs in each list orthographically related and half unrelated. The related pairs in List A were changed to unrelated pairs in List B, and vice versa.

An additional 144 filler items were included. These included three groups of 48 prime-target pairs (word-pseudoword, pseudoword-word, and pseudoword-pseudoword). As with the experimental group, related and unrelated conditions were developed for each of the filler item groups. Half of the related pairs and half of the unrelated pairs were placed on List A, and the other half were placed on List B. With the filler items included, each list contained 192 prime-target pairs. List A and List B were then each divided in half, with an equal number of related and unrelated pairs from each group in each half.

\section{Apparatus}

An Apple MacIntosh LC III computer with a MacIntosh color display monitor was used for all of the tasks. The application program PsyScope (Cohen, MacWhinney, Flatt, \& Provost, 1993) was used to display stimuli and to time the participants' responses to the nearest millisecond. The computer was interfaced with a PsyScope Model 
Mk6 button box. A Realistic 33-1060 electret condenser microphone, connected to the button box, was used in the pseudoword naming task.

\section{Procedure}

The participants were tested individually in one 40 -min session. The order of presentation of the tasks was lexical decision, form priming, homophone choice, and pseudoword naming. A block of 10 practice trials ( 14 for pseudoword naming) preceded each experimental task. For all tasks except pseudoword naming, stimuli within a block of trials were presented in a different random order for each participant. Stimuli were presented in the center of the computer monitor in Chicago 12-point font. The participants were asked to respond as quickly and accurately as possible. Target stimuli remained on the screen until a response was made.

Lexical decision task. The participants were presented with a series of letter strings. Their task was to decide whether or not each letter string was a word and to press the corresponding button on the button box. Each trial began with a fixation point in the center of the monitor, which remained on the screen for $500 \mathrm{msec}$. This was immediately replaced by the target stimulus, in lowercase letters. The intertrial interval (ITI) was $1,000 \mathrm{msec}$.

Form priming task. The participants were informed that a series of " $\&$ " symbols would appear before each target stimulus. Each target would be presented in uppercase letters, and they were to indicate whether or not each was a real word. No mention was made of the primes, which were presented in lowercase letters. The 192 experimental trials were split into two blocks, with 96 trials in each. The participants were shown the two halves of either the A list or the B list. Each half list was presented equally often in the first and second blocks. Each trial began with a mask ( $\& \& \& \& \&$ ) presented for $500 \mathrm{msec}$. This was replaced immediately by the prime, which remained on the screen for $30 \mathrm{msec}$ in the first block of trials and $60 \mathrm{msec}$ in the second block of trials. The target immediately replaced the prime. The ITI was $1,000 \mathrm{msec}$.

Homophone choice task. On each trial, the participants were shown a word for $1,000 \mathrm{msec}$. The screen was blank for $500 \mathrm{msec}$ and then a pair of homophones was presented on the same line of the screen. The participants' task was to indicate whether the homophone on the left or on the right was a synonym of the preceding word by pressing the corresponding button on the button box. The ITI was $750 \mathrm{msec}$. Each participant received one of the two lists of homophones.

Pseudoword naming task. Pseudowords were presented one at a time, and the participants were instructed to pronounce each item aloud into the microphone. The list of pseudowords was randomized and presented in the same order to all participants. The computer timed response latencies from the onset of the stimulus to the onset of the participant's voice. The ITI was $1,500 \mathrm{msec}$. The experimenter recorded the participants' incorrect pronunciations by hand.

\section{RESULTS}

The mean score on the ART for the low-print-exposure group was $11.3(S E=2.77)$ and for the high-printexposure group was $22.3(S E=0.55)$. This difference was significant $[t(62)=15.02, p<.001]$. The mean raw score on the Nelson-Denny comprehension test for the lowprint-exposure group was $20.6(S E=0.45)$ and for the high-print-exposure group was $21.4(S E=0.48)$. This difference was not significant $[t(62)=1.29, p=.20]$.

For each of the experimental tasks, response latencies greater than 3 standard deviations from the participant's mean correct response latency and latencies less than $250 \mathrm{msec}$ were discarded. A similar number of scores was discarded for each print exposure group on each task. Analyses were conducted on both subject $(F 1)$ and item $(F 2)$ means. Exposure to print (high, low) was treated as a between-subjects variable and as a within-items variable. All other variables were treated as within-subjects and between-items variables, except where noted. Means presented in the text and tables are subject means.

The response latency variances for the low-printexposure group were considerably larger than the variances for the high-print-exposure group, violating the assumption of homogeneity of variance in an analysis of variance (ANOVA) test. Although these tests are known to remain robust if $N$ s are equal (Myers \& Wells, 1991), as was the case in the present study, analyses were also conducted with transformed data (logarithmic), which reduced the heterogeneity of variance. The results from the analyses on the transformed data, however, were essentially the same as with the original data, and, therefore, only the latter are presented.

\section{Homophone Choice Task}

Trimming the data eliminated $1.0 \%$ of the responses. The variables in the ANOVAs were exposure to print, frequency of the correct homophone (high, low), and position of the correct homophone (left, right). However, because there were no significant main effects or interactions with target position, the results presented below are collapsed across position. Mean decision latencies and error percentages are presented in Table 1.

The high-print-exposure group produced significantly faster decision latencies than did the low-print-exposure group $\left[F 1(1,62)=10.91, M S_{\mathrm{e}}=193,124.9, p<.01\right.$; $\left.F 2(1,78)=190.24, M S_{\mathrm{e}}=16,963.0, p<.0001\right]$ and made significantly fewer errors $\left[F 1(1,62)=11.68, M S_{\mathrm{e}}=0.037\right.$, $\left.p<.01 ; F 2(1,78)=139.65, M S_{\mathrm{e}}=0.004, p<.001\right]$. In the latency data, the interaction between exposure to print and target frequency approached significance by subjects $\left[F 1(1,62)=3.10, M S_{\mathrm{e}}=14,547.6, p=.083\right]$ and was significant by items $\left[F 2(1,78)=5.33, M S_{\mathrm{e}}=\right.$ $16,963.0, p<.05]$. The frequency effect for the highprint-exposure participants was $76 \mathrm{msec}$ smaller than for the low-print-exposure participants. Simple main effect tests revealed that the effect of exposure to print was significant for both high-frequency words $[F 1(1,71)=7.39$, $M S_{\mathrm{e}}=103,836.2, p<.01 ; F 2(1,78)=65.95, M S_{\mathrm{e}}=$ $16,963.0, p<.001]$ and low-frequency words $[F 1(1,71)=$ $13.34, M S_{\mathrm{e}}=103,836.2, p<.001 ; F 2(1,78)=129.62$, $\left.M S_{\mathrm{e}}=16,963.0, p<.0001\right]$. In the error data, the inter-

Table 1

Mean Decision Latencies (in Milliseconds) and

Error Rates (in Percentages) for the Homophone Choice Task

\begin{tabular}{cccccc}
\hline & \multicolumn{3}{c}{ Exposure to Print } \\
\cline { 2 - 3 } \cline { 5 - 6 } Target Type & \multicolumn{2}{c}{ High } & & \multicolumn{2}{c}{ Low } \\
\cline { 2 - 3 } \cline { 5 - 6 } High frequency & 1.036 & 8.4 & & 1,255 & 19.8 \\
Low frequency & 1,139 & 16.2 & & 1,434 & 28.0 \\
\hline
\end{tabular}


Table 2

Mean Decision Latencies (in Milliseconds) and Error Rates (in Percentages) for the Lexical Decision Task

\begin{tabular}{|c|c|c|c|c|}
\hline \multirow[b]{3}{*}{ Stimulus Type } & \multicolumn{4}{|c|}{ Exposure to Print } \\
\hline & \multicolumn{2}{|c|}{ High } & \multicolumn{2}{|c|}{ Low } \\
\hline & Latency & $\%$ Errors & Latency & $\%$ Errors \\
\hline \multicolumn{5}{|c|}{ Words } \\
\hline \multicolumn{5}{|l|}{ High Frequency } \\
\hline Large neighborhood & 533 & 1.0 & 621 & 1.3 \\
\hline Small neighborhood & 542 & 1.6 & 616 & 1.3 \\
\hline \multicolumn{5}{|l|}{ Low Frequency } \\
\hline Large neighborhood & 636 & 9.4 & 840 & 13.3 \\
\hline Small neighborhood & 694 & 34.0 & 952 & 44.4 \\
\hline \multicolumn{5}{|c|}{ Pseudohomophones } \\
\hline Unusual orthographic pattern & 627 & 1.1 & 804 & 0.6 \\
\hline Common orthographic pattern & 743 & 10.7 & 1,024 & 15.3 \\
\hline
\end{tabular}

action between exposure to print and target frequency was not significant $\left(F_{\mathrm{S}}<1\right)$.

\section{Lexical Decision Task}

Words. Trimming the data eliminated $1.7 \%$ of the responses. Variables in the ANOVAs were exposure to print, word frequency (high, low), and neighborhood size (small, large). Mean decision latencies and error percentages are presented in Table 2.

The high-print-exposure group produced significantly faster decision latencies than did the low-print-exposure group $\left[F 1(1,62)=12.50, M S_{\mathrm{e}}=124,281.0, p<.001\right.$; $\left.F 2(1,44)=120.30, M S_{\mathrm{e}}=7,023.9, p<.0001\right]$ and also significantly fewer errors $\left[F 1(1,62)=8.07, M S_{\mathrm{e}}=0.010\right.$, $\left.p<.01 ; F 2(1,44)=10.70, M S_{\mathrm{e}}=.003, p<.01\right]$. The interaction between exposure to print and word frequency was significant in the latency analyses $[F](1,62)=16.08$, $M S_{\mathrm{e}}=22,487.0, p<.001 ; F 2(1,44)=39.37, M S_{\mathrm{e}}=$ $7,023.9, p<.001]$ and in the error analyses $[F 1(1,62)=$ $8.88, M S_{\mathrm{e}}=0.009, p<.01 ; F 2(1,44)=10.77, M S_{\mathrm{e}}=$ $0.003, p<.01]$. The frequency effect for the high-printexposure participants was $150 \mathrm{msec}$ smaller than for the low-print-exposure participants. Simple main effect tests revealed that the effect of exposure to print was significant for low-frequency words in both the latency data $(231 \mathrm{msec})\left[F 1(1,84)=23.26, M S_{\mathrm{e}}=73,384.0, p<.001\right.$; $\left.F 2(1,44)=148.65, M S_{\mathrm{e}}=7,023.9, p<.001\right]$ and the error data $(8.0 \%)\left[F 1(1,124)=16.92, M S_{\mathrm{e}}=0.010, p<\right.$ $\left..001 ; F 2(1,44)=21.47, M S_{\mathrm{e}}=0.003, p<.001\right]$. The effect of exposure to print was weaker for high-frequency words $(81 \mathrm{msec}$ and $0.1 \%$ errors $)$. In the latency data, this effect approached significance by subjects $[F 1(1,84)=$ 2.84, $\left.M S_{\mathrm{e}}=73,384.0, p<.10\right]$ and was significant by items $\left[F 2(1,44)=11.02, M S_{\mathrm{e}}=7,023.9, p<.01\right]$, but it was not significant in the error analyses $\left(F_{\mathrm{S}}<1\right)$. The interaction between exposure to print and neighborhood size was not significant in the latency analyses $[F 1<1$; $\left.F 2(1,44)=3.55, M S_{\mathrm{e}}=7,023.9, p>.05\right]$ or in the error analyses $\left[F 1(1,62)=2.04, M S_{\mathrm{e}}=0.007, p>.05 ; F 2(1,44)\right.$ $\left.=1.78, M S_{\mathrm{e}}=0.003, p>.05\right]$.
In the latency data, the triple interaction between exposure to print, word frequency, and neighborhood size was not significant by subjects $\left[F 1(1,62)=1.80, M S_{\mathrm{e}}=\right.$ $11,060.8, p>.05]$ but was significant by items $[F 2(1,44)=$ $\left.5.91, M S_{\mathrm{e}}=7,023.9, p<.05\right]$. The low-print-exposure group produced a larger effect of neighborhood size for low-frequency words (112 msec) than did the high-printexposure group ( $58 \mathrm{msec})$. In the error analyses, the triple interaction approached significance by subjects $\left[F 1(1,62)=3.41, M S_{\mathrm{e}}=0.006, p=.07\right]$ but was not significant by items $\left[F 2(1,44)=2.46, M S_{\mathrm{e}}=0.003, p>.05\right]$. Again, the low-print-exposure group produced a larger effect of neighborhood size for low-frequency words $(31.1 \%)$ than did the high-print-exposure group (24.6\%).

The high error rates for the low-frequency/smallneighborhood items in this task are somewhat surprising. One possible explanation for the high error rates, however, is that the participants in the present study did not know some of the low-frequency/small-neighborhood words. The error rates on several of the low-frequency/ small-neighborhood items were extremely high, suggesting that this was the case. In particular, both print-exposure groups had error rates over $50 \%$ on the items FIFE, WAIF, GOUT, and DEEM. With these items removed from the analyses, the error rate for the low-frequency/smallneighborhood words dropped from $34.0 \%$ to $18.2 \%$ for the high-print-exposure group and from $44.4 \%$ to $27.5 \%$ for the low-print-exposure group. Importantly, the pattern of results in both the latency and the error data did not change with these items removed.

Pseudohomophone distractors. Trimming the data eliminated $1.6 \%$ of the responses. The variables in the ANOVAs were exposure to print and orthographic typicality (high, low). Mean decision latencies and error percentages are presented in Table 2 .

The high-print-exposure group rejected pseudohomophones significantly faster than did the low-print-exposure group $\left[F 1(1,62)=12.35, M S_{\mathrm{e}}=135,950.7, p<.001\right.$; $\left.F 2(1,38)=250.37, M S_{\mathrm{e}}=4,069.4, p<.0001\right]$. The effect of exposure to print was not significant in the error data $\left[F 1(1,62)=1.88, M S_{\mathrm{e}}=0.007, p>.05 ; F 2(1,38)=\right.$ $\left.2.14, M S_{\mathrm{e}}=0.005, p>.05\right]$. The interaction between exposure to print and orthographic typicality was significant in the latency analyses $\left[F 1(1,62)=7.00, M S_{\mathrm{e}}=\right.$ $12,155.5, p<.01 ; F 2(1,38)=10.91, M S_{\mathrm{e}}=4,069.4, p<$ $.01]$. The effect of orthographic typicality was larger for the low-print-exposure group (220 $\mathrm{msec})$ than for the high-print-exposure group (116 msec). Alternatively, the effect of print exposure was smaller for pseudohomophones with unusual orthographic patterns $[F 1(1,73)=$ $6.80, M S_{\mathrm{e}}=74,053.1, p<.05 ; F 2(1,38)=78.37, M S_{\mathrm{e}}=$ $4,069.4, p<.001]$ than for pseudohomophones with common orthographic patterns $\left[F 1(1,73)=17.01, M S_{\mathrm{e}}=\right.$ $74,053.1, p<.001 ; F 2(1,38)=182.91, M S_{\mathrm{e}}=4,069.4, p<$ .0011 . In the error analyses, the interaction between exposure to print and orthographic typicality approached significance by subjects $\left[F 1(1,62)=3.21, M S_{\mathrm{e}}=0.006\right.$, 
$p=.078]$ and by items $\left[F 2(1,38)=3.13, M S_{\mathrm{e}}=0.005\right.$, $p=.085]$. The effect of orthographic typicality was larger for the low-print-exposure group $(14.7 \%)$ than for the high-print-exposure group $(9.6 \%)$. Further analyses indicated that the high-print-exposure group made significantly fewer errors than did the low-print-exposure group on the pseudohomophones with common orthographic patterns $\left[F 1(1,124)=4.95, M S_{\mathrm{e}}=0.007, p<\right.$ $\left..05 ; F 2(1,38)=5.22, M S_{\mathrm{e}}=0.005, p<.05\right]$ but there was no effect of exposure to print for the pseudohomophones with unusual orthographic patterns $\left(F_{\mathrm{S}}<1\right)$.

\section{Pseudoword Naming Task}

Trimming the data eliminated $1.2 \%$ of the responses. The variables in the ANOVAs were exposure to print and item length (one syllable, two syllable). Mean naming latencies and error percentages are presented in Table 3.

The high-print-exposure group had significantly faster naming latencies than did the low-print-exposure group $\left[F 1(1,62)=6.05, M S_{\mathrm{e}}=131,461.1, p<.05 ; F 2(1,78)=\right.$ $\left.446.01, M S_{\mathrm{e}}=2,074.9, p<.0001\right]$ and made significantly fewer errors $\left[F 1(1,62)=19.44, M S_{\mathrm{e}}=0.004, p<.001\right.$; $\left.F 2(1,78)=47.52, M S_{\mathrm{e}}=0.003, p<.0001\right]$. In the latency analyses, the interaction between exposure to print and item length was not significant by subjects $[F 1(1,62)=$ 1.51, $\left.M S_{\mathrm{e}}=15,828.0, p>.05\right]$ but was significant by items $\left[F 2(1,78)=12.51, M S_{\mathrm{e}}=2,074.9, p<.001\right]$. The effect of item length was smaller for the high-printexposure participants than for the low-print-exposure participants. In the error analyses, the interaction between exposure to print and item length was not significant $(F \mathrm{~s}<1.1)$.

\section{Form Priming Task}

Trimming the data eliminated $2.0 \%$ of the responses. The variables in the ANOVAs were exposure to print, prime frequency (high, low), prime duration ( $30 \mathrm{msec}$, $60 \mathrm{msec}$ ), and prime relatedness (related, unrelated). In the items analyses, prime duration and prime relatedness were treated as within-items variables. Mean decision latencies and error percentages are presented in Table 4.

The high-print-exposure group had significantly faster decision latencies than the low-print-exposure group $\left[F 1(1,62)=8.96, M S_{\mathrm{e}}=88,289.0, p<.01 ; F 2(1,46)=\right.$ $\left.56.11, M S_{\mathrm{e}}=10,096.4, p<.0001\right]$. The high-printexposure participants produced fewer errors than did the low-print-exposure participants; the difference was not

Table 3

Mean Naming Latencies (in Milliseconds) and Error Rates (in Percentages) for the Pseudoword Naming Task

\begin{tabular}{lccccc}
\hline & \multicolumn{3}{c}{ Exposure to Print } \\
\cline { 2 - 3 } \cline { 5 - 6 } Item Length & \multicolumn{2}{c}{ High } & & \multicolumn{2}{c}{ Low } \\
\cline { 2 - 3 } \cline { 5 - 6 } & Latency & \% Errors & & Latency & \% Errors \\
\hline One syllable & 668 & 3.4 & & 798 & 7.9 \\
Two syllable & 846 & 6.3 & & 1,031 & 12.0 \\
\hline
\end{tabular}

significant by subjects $(F 1<1)$ but approached significance by items $\left[F 2(1,46)=3.66, M S_{\mathrm{e}}=0.049, p=.06\right]$.

The interaction between exposure to print and prime relatedness was not significant either in the latency data or in the error data $(F \mathrm{~s}<1.2)$. Only one of the three-way and four-way interactions was significant. The three-way interaction between exposure to print, prime relatedness, and prime duration was significant in the latency analy$\operatorname{sis}\left[F 1(1,62)=8.93, M S_{\mathrm{e}}=4,371.4, p<.01 ; F 2(1,46)=\right.$ $\left.8.43, M S_{\mathrm{e}}=4,744.1, p<.01\right]$. This interaction was explored by conducting separate three-way ANOVAs on the latency data for each group. No significant effects were observed in the analyses of the data for the lowprint-exposure group.

The high-print-exposure group produced a significant interaction between prime relatedness and prime duration $\left[F 1(1,31)=10.86, M S_{\mathrm{e}}=4,493.9, p<.01 ; F 2(1,46)=\right.$ $\left.10.04, M S_{\mathrm{e}}=2,921.6, p<.01\right]$ and a significant interaction between prime relatedness and prime frequency in the subjects analysis $\left[F 1(1,31)=7.07, M S_{\mathrm{e}}=3,185.1\right.$, $p<.05]$ but not in the items analysis $[F 2(1,46)=2.43$, $\left.M S_{\mathrm{e}}=10,014.7, p>.05\right]$. Four planned comparisons using the Bonferroni $t$ statistic were conducted, and two significant differences were observed. First, for highfrequency primes presented for $30 \mathrm{msec}$, decision latencies to targets preceded by related primes were significantly faster than decision latencies to unrelated primes $[t(62)=2.59, p<.05]$. Second, for low-frequency primes presented for $60 \mathrm{msec}$, decision latencies to targets preceded by related primes were significantly longer than decision latencies to unrelated primes $[t(62)=2.67, p<.05]$.

\section{DISCUSSION}

This study has demonstrated that, even among very successful students (i.e., high school students who make it to university), those who do a lot of reading for pleasure have more efficient word recognition processes than do students who read much less. Significant differences between high- and low-print-exposure participants were found both on the phonological task and on the orthographic tasks even though the two groups of participants were matched on Nelson-Denny reading comprehension test scores. Matching the two groups of participants in this way allows us to be fairly confident that observed differences between the groups were due to differences in exposure to print and not to differences in general verbal ability. However, because efficient word recognition skills are associated with better reading comprehension (e.g., Perfetti, 1985), this matching procedure very likely underestimated the benefits of exposure to print. The real impact of exposure to print on word recognition processes is likely to be very substantial indeed.

The results of the present study replicated and extended Stanovich and West's (1989) findings. Stanovich and West found a significant correlation between ART scores and pseudoword naming ability. Consistent with their finding, the participants in this study who were high in ex- 
Table 4

Mean Decision Latencies (in Milliseconds) and

Error Rates (in Percentages) in the Form Priming Task

\begin{tabular}{|c|c|c|c|c|c|c|}
\hline \multirow[b]{3}{*}{ Prime Type } & \multicolumn{4}{|c|}{ Prime } & \multirow{2}{*}{\multicolumn{2}{|c|}{ Priming Effect }} \\
\hline & \multicolumn{2}{|c|}{ Related } & \multicolumn{2}{|c|}{ Unrelated } & & \\
\hline & Latency & $\%$ Errors & Latency & $\%$ Errors & Latency & $\%$ Errors \\
\hline \multicolumn{7}{|c|}{ High Print Exposure } \\
\hline \multicolumn{7}{|c|}{ High Frequency } \\
\hline $30 \mathrm{msec}$ & 632 & 17.4 & 678 & 12.5 & $46^{*}$ & -4.9 \\
\hline $60 \mathrm{msec}$ & 691 & 14.4 & 666 & 9.5 & -25 & -4.9 \\
\hline \multicolumn{7}{|c|}{ Low Frequency } \\
\hline $30 \mathrm{msec}$ & 616 & 8.5 & 609 & 13.5 & -7 & 6.0 \\
\hline \multirow[t]{2}{*}{$60 \mathrm{msec}$} & 679 & 12.2 & 632 & 4.7 & $-47^{*}$ & -7.5 \\
\hline & \multicolumn{4}{|c|}{ Low Print Exposure } & & \\
\hline \multicolumn{7}{|c|}{ High Frequency } \\
\hline $30 \mathrm{msec}$ & 736 & 21.5 & 726 & 12.5 & 12 & -9.0 \\
\hline $60 \mathrm{msec}$ & 734 & 15.0 & 770 & 6.4 & 36 & -8.6 \\
\hline \multicolumn{7}{|c|}{ Low Frequency } \\
\hline $30 \mathrm{msec}$ & 702 & 6.3 & 696 & 10.4 & -6 & 4.1 \\
\hline $60 \mathrm{msec}$ & 747 & 12.5 & 724 & 3.8 & -23 & -8.7 \\
\hline
\end{tabular}

posure to print were significantly faster and more accurate in naming pseudowords than were the low-print-exposure participants. These results suggest that exposure to print enhances a reader's spelling-sound translation processes. Because the participants in the present study were matched for reading comprehension ability, we can be more certain than Stanovich and West that our effect of exposure to print is not instead an effect of verbal ability.

Our results are also in agreement with Stanovich and West's (1989) findings that suggest that exposure to print enhances knowledge of the orthographic patterns of English and the efficiency with which that knowledge can be used in word recognition. Stanovich and West observed significant correlations between ART scores and performance on both a homophone choice task and an orthographic choice task. Consistent with their finding for the homophone choice task, our high-print-exposure participants performed the homophone choice task more quickly and accurately than did our low-print-exposure participants.

Both of Stanovich and West's (1989) orthographic tasks involved reading two words on each trial. These tasks produce long decision latencies and may involve decision processes not used when only a single stimulus is presented. The present study extended Stanovich and West's work by including an orthographic task that involved reading only one stimulus at a time: lexical decision with pseudohomophone distractors. The high-print-exposure participants made significantly faster decisions on both words and pseudohomophones than did the low-printexposure participants, and they made significantly more accurate decisions on word stimuli. These findings provide additional support for the view that exposure to print enhances orthographic knowledge.

In both orthographic tasks in the present study, there was a smaller effect of word frequency for the high-printexposure participants than for the low-print-exposure par- ticipants. This finding is consistent with the view that the benefits of exposure to a word decrease with increasing exposures (Van Orden et al., 1990). The high-printexposure participants produced a smaller effect of neighborhood size for low-frequency words than did the lowprint-exposure participants. The high-print-exposure participants also produced a smaller effect of orthographic typicality on pseudohomophone decisions than did the low-print-exposure participants. In other words, the highprint-exposure participants were able to more quickly accept unword-like words and more quickly reject wordlike pseudowords than were the low-print-exposure participants. Such a finding is further evidence that exposure to print enhances orthographic knowledge.

A final finding of the present study was that the relative speed with which orthographic and phonological representations were activated differed for participants with high and low levels of exposure to print. For the highprint-exposure group, high-frequency primes produced strong facilitation for touch-COUCH pairs when presented for $30 \mathrm{msec}$ and inhibition when presented for $60 \mathrm{msec}$. These results suggest that high-print-exposure participants quickly activate a robust orthographic representation when reading a familiar word, and, shortly thereafter, a phonological representation of the word becomes more strongly activated than the orthographic representation. This pattern is consistent with Ferrand and Grainger's $(1992,1993,1994)$ findings. In contrast, the lowprint-exposure group did not show significant facilitation or inhibition from high-frequency primes at either prime duration. This may indicate that both orthographic and phonological representations are activated more slowly for low-print-exposure participants than for high-printexposure participants, and, when activated, both representations are activated to a similar degree. A major difference, then, between high- and low-print-exposure participants is that high-print-exposure participants seem 
to be able to more quickly and strongly activate orthographic representations of common words, probably because of their greater familiarity with the orthographic patterns of the language. High-print-exposure participants subsequently more quickly and strongly activate the corresponding phonology of common words than do lowprint-exposure participants, probably because of their more thorough knowledge of spelling-sound correspondences and the greater efficiency of their translation processes.

The pattern of the results for the high- and low-printexposure participants was more similar when primes were low-frequency words. For the high-print-exposure participants, low-frequency primes produced neither facilitation nor inhibition at $30 \mathrm{msec}$ followed by strong inhibition at $60 \mathrm{msec}$. These results suggest that neither representation was strongly activated initially, but then the phonological representation became highly activated. Again, the low-print-exposure group did not show significant facilitation or inhibition at either prime duration; however, they did show a trend toward inhibition with the 60 -msec duration, suggesting that they activated phonological representations more slowly than did the highprint-exposure participants.

In summary, the results from the four tasks in this study show that there are substantial differences in word recognition skills between people who differ in their exposure to print. Although it may seem obvious that any system should improve with practice, the differences are more dramatic than one might expect, given that the two groups were equated in terms of reading comprehension ability. The pattern of results over the four tasks clearly indicates that practice in reading is associated with both an increase in the ability to use knowledge of the relationships between orthography and meaning and an increase in the ability to use knowledge of the relationships between orthography and phonology.

\section{Why Poor Word Recognition and \\ Good Reading Comprehension?}

An interesting question raised by the results of this study is how the low-print-exposure group, with much weaker word recognition skills than the high-printexposure group, obtained similar scores on the NelsonDenny reading comprehension test. Research has shown that word recognition skills are associated with reading comprehension ability (Perfetti, 1985). Furthermore, Stanovich, Feeman, and Cunningham (1983) found that word recognition skills contribute to reading ability in children. By equating the two groups on reading comprehension ability, one might have expected their performance on the word recognition tasks to be similar.

One possible explanation for the equivalent performance of the two groups on the Nelson-Denny reading comprehension test is that the low-print-exposure group in fact had poorer reading comprehension abilities, but their scores on the test were inflated by superior test-taking skills (e.g., Lifson, Scraggs, \& Bennion, 1984). A second, and more interesting, possibility is that the low-print-exposure participants made use of other skills involved in reading to compensate for less efficient word recognition processes. Bruck and Waters (1990) compared the performance of two groups of sixth grade students who scored similarly on a standardized reading comprehension test but differed considerably in their performance on a spelling test. Like our low-print-exposure participants, the poor spellers had weak word recognition skills when tested on words presented in isolation. However, in a sentence reading task, the poor spellers were observed to use context to facilitate word recognition, whereas the good spellers did not. In the present study, the low-print-exposure group may have made use of some compensatory skills in reading, such as the use of context, to make up for their less efficient word recognition skills, resulting in equivalent performance on the reading comprehension test.

\section{Implications of the Present Study}

There is considerable debate among word recognition researchers concerning the relative importance of the orthography-meaning route and the phonological route to the activation of word meanings in skilled silent reading. Views range from a primary role for the phonological route (e.g., Van Orden et al., 1990) to a primary role for the orthography-meaning route (e.g., Daneman, Reingold, \& Davidson, 1995). None of the studies used in support of each position have included an assessment of the level of exposure to print of the participants. It is possible that both positions are correct but that they apply to readers with different levels of exposure to print. For readers with a high level of exposure to print, the orthography-meaning route may play a primary role, particularly for high-frequency words, because they have superior orthographic knowledge. In contrast, readers with a lower level of exposure to print have less efficient orthographic processes, which may allow for a greater role for phonology.

\section{Conclusion}

The results of the present study suggest that the list of cognitive benefits that are attributable to print exposure includes not only increases in vocabulary and general knowledge, as Stanovich and Cunningham (1992) observed, but also enhancement of word recognition processes. Taken together, these studies provide a strong argument for teachers and parents to encourage children to read widely.

\section{REFERENCES}

Allen, L., Cipielewski, J., \& Stanovich, K. E. (1992). Multiple indicators of children's reading habits and attitudes: Construct validity and cognitive correlates. Journal of Educational Psychology, 84, 489-503

ANDREWS, S. (1992). Frequency and neighborhood effects on lexical access: Lexical similarity or orthographic redundancy? Journal of Experimental Psychology: Learning, Memory, \& Cognition, 18, 234-254.

Brown, J. I., BennetT, J. M., \& Hanna, G. (1981). The Nelson-Denny Reading Test. Chicago: Riverside. 
Brown, P., LuPKer, S. J., \& Colombo, L. (1994). Interacting sources of information in word naming: A study of individual differences. Journal of Experimental Psychology: Human Perception \& Performance, 20, 537-554.

Bruck, M., \& Waters, G. S. (1990). An analysis of the component spelling and reading skills of good readers-good spellers, good readerspoor spellers, and poor readers--poor spellers. In T. H. Carr \& B. A. Levy (Eds.), Reading and its development: Component skills approaches (pp. 161-206). San Diego: Academic Press.

BURT, C. D. B., \& KeMP, S. (1991). Retrospective duration estimation of public events. Memory \& Cognition, 19, 252-262.

Cipielewski, J., \& Stanovich, K. E. (1992). Predicting growth in reading ability from children's exposure to print. Journal of Experimental Child Psychology, 54, 74-89.

Cohen, J., MacWhinney, B., Flatt, M., \& Provost, J. (1993). PsyScope: An interactive graphic system for designing and controlling experiments in the psychology laboratory using Macintosh computers. Behavior Research Methods, Instruments, \& Computers, 25, 257-271.

Coltheart, M., Davelaar, E., Jonasson, J. T., \& Besner, D. (1977) Access to the internal lexicon. In S. Dornic (Ed.), Attention and performance VI (pp. 535-555). New York: Academic Press.

Daneman, M., Reingold, E. M., \& Davidson, M. (1995). Time course of phonological activation during reading: Evidence from eye fixations. Journal of Experimental Psychology: Learning, Memory, \& Cognition, 21, 884-898.

Ferrand, L., \& Grainger, J. (1992). Phonology and orthography in visual word recognition: Evidence from masked non-word priming. Quarterly Journal of Experimental Psychology, 45A, 353-372.

Ferrand, L., \& Grainger, J. (1993). The time course of orthographic and phonological code activation in the early phases of visual word recognition. Bulletin of the Psychonomic Society, 31, 119-122.

FERRAND, L., \& Grainger, J. (1994). Effects of orthography are independent of phonology in masked form priming. Quarterly Journal of Experimental Psychology, 47A, 365-382.

FORSTER, K. I. (1987). Form-priming with masked primes: The best match hypothesis. In M. Coltheart (Ed.), Attention and performance XII (pp. 127-146). Hillsdale, NJ: Erlbaum.

FoRSTER, K. I., \& DAVIS, C. (1991). The density constraint on form priming in the naming task: Interference effects from a masked prime. Journal of Memory \& Language, 30, 1-25.

GUTHRIE, J. T. (1981). Reading in New Zealand: Achievement and volume. Reading Research Quarterly, 17, 6-27.

HAYES, D. P., \& AHRENS, M. (1988). Vocabulary simplification for children: A special case of motherese? Journal of Child Language, 15 , 395-410.

JARED, D., LeVY, B. A., \& RAYNER, K. (1999). The role of phonology in the activation of word meanings during reading: Evidence from proofreading and eye movements. Journal of Experimental Psychology: General, 128, 219-264.

Kučera, H., \& FrancIs, W. N. (1967). Computational analysis of present-day American English. Providence, RI: Brown University Press.

Lewellen, M. J., Goldinger, S. D., Pisoni, D. E., \& Greene, B. G.
(1993). Lexical familiarity and processing efficiency: Individual differences in naming, lexical decision, and semantic categorization. Journal of Experimental Psychology: General, 122, 316-330.

Lifson, S., Scraggs, T., \& Bennion, K. E. (1984). Passage independence in reading achievement tests: A follow-up. Perceptual \& Motor Skills, 58, 945-946.

McBride-Chang, C., Manis, F. R., Seidenberg, M. S., Custodio, R. G., \& Dol, L. M. (1993). Print exposure as a predictor of word reading and reading comprehension in disabled and nondisabled readers. Journal of Educational Psychology, 85, 230-238.

MyERS, J. L., \& WeLls, A. D. (1991). Research design and statistical analysis. New York: HarperCollins.

Paulhus, D. L. (1984). Two-component models of socially desirable responding. Journal of Personality \& Social Psychology, 46, 598-609.

Perfetti, C. A. (1985). Reading ability. New York: Oxford University Press.

Solso, R. L., \& Juel, C. L. (1980). Positional frequency and versatility of bigrams for two- through nine-letter English words. Behavior Research Methods \& Instrumentation, 12, 297-343.

Stanovich, K. E. (1993). Does reading make you smarter? Literacy and the development of verbal intelligence. In H. Reese (Ed.), $A d$ vances in child development and behavior (Vol. 24, pp. 133-180). San Diego: Academic Press

Stanovich, K. E., \& Cunningham, A. E. (1992), Studying the consequences of literacy within a literate society: The cognitive correlates of print exposure. Mcmory \& Cognition, 20, 51-68.

Stanovich, K. E., Feeman, D. J., \& Cunningham, A. E. (1983). The development of the relation between letter-naming speed and reading ability. Bulletin of the Psychonomic Society, 21, 199-202.

STANOVICH, K. E., \& WEST, R. F. (1989). Exposure to print and orthographic processing. Reading Research Quarterly, 24, 402-433.

VAN ORDEN, G. C. (1987). A ROWS is a ROSE: Spelling, sound, and reading. Memory \& Cognition, 15, 181-198.

Van Orden, G. C., Pennington, B. F., \& Stone, G. O. (1990). Word identification in reading and the promise of subsymbolic psycholinguistics. Psychological Review, 97, 488-522.

WALBERG, H. J., \& TSAI, S. (1984). Matthew effects in education. American Educational Research Journal, 20, 442-451.

West, R. F., Stanovich, K. E., \& Mitchell, H. R. (1993). Reading in the real world and its correlates. Reading Research Quarterly, 28, $35-50$.

\section{NOTES}

1. In this paper, we examine whether exposure to print results in greater efficiency in the use of knowledge of the relationships between orthography and meaning. If such gains in efficiency are observed, future research will need to determine whether they result from greater efficiency in bottom-up activation of meaning from orthography, greater efficiency in top-down activation of orthography from meaning (e.g., spelling verification), or both. In the tasks of this study, we did not distinguish between these possibilities.

2 . The word frequencies reported here are frequencies per million words taken from the norms of Kučera and Francis (1967). 
APPENDIX A

Pseudohomophones Presented in the Lexical Decision Task

\begin{tabular}{cc}
\hline $\begin{array}{c}\text { Common } \\
\text { Orthographic Pattern }\end{array}$ & $\begin{array}{c}\text { Unusual } \\
\text { Orthographic Pattern }\end{array}$ \\
\hline breef & cawph \\
chete & chuze \\
crule & cryde \\
fale & dawg \\
frate & fayze \\
grean & gardz \\
hait & jrive \\
hored & kohm \\
neace & kohte \\
perse & krinj \\
plite & kwene \\
reech & leehv \\
saive & perje \\
sirch & phlak \\
sope & shawt \\
stoar & spooq \\
taist & survd \\
turse & waije \\
werth & wohk \\
whied & yurnn \\
\hline
\end{tabular}

APPENDIX B

Stimuli Presented in the

Form Priming Lexical Decision Task

\begin{tabular}{|c|c|c|c|c|c|}
\hline \multicolumn{3}{|c|}{ Low-Frequency Primes } & \multicolumn{3}{|c|}{ High-Frequency Primes } \\
\hline Related & Unrelated & Target & Related & Unrelated & Target \\
\hline ton & sew & CON & bad & put & WAD \\
\hline sew & ton & DEW & put & bad & NUT \\
\hline hoof & bush & GOOF & move & what & COVE \\
\hline bush & hoof & LUSH & what & move & CHAT \\
\hline bough & swamp & $\mathrm{COUGH}$ & south & break & COUTH \\
\hline swamp & bough & STAMP & break & south & BLEAK \\
\hline soot & deaf & LOOT & word & want & CORD \\
\hline deaf & soot & LEAF & want & word & RANT \\
\hline bowl & caste & HOWL & said & soul & RAID \\
\hline caste & bowl & PASTE & soul & said & FOUL \\
\hline skied & lease & SHIED & phase & blood & CHASE \\
\hline lease & skied & TEASE & blood & phase & BROOD \\
\hline pint & pour & HINT & some & says & DOME \\
\hline doll & steak & TOLL & says & some & PAYS \\
\hline pour & pint & SOUR & both & sure & МОТН \\
\hline dose & wash & POSE & sure & both & CURE \\
\hline wash & dose & MASH & shall & touch & STALL \\
\hline blown & swear & CLOWN & touch & shall & $\mathrm{COUCH}$ \\
\hline swear & blown & SMEAR & shook & head & SPOOK \\
\hline steak & doll & SNEAK & head & shook & BEAD \\
\hline null & shove & BULL & have & gross & CAVE \\
\hline shone & pear & SCONE & gross & have & GLOSS \\
\hline shove & null & STOVE & could & give & MOULD \\
\hline pear & shone & GEAR & give & could & DIVE \\
\hline
\end{tabular}

